\title{
El ciclo de la calle. Reivindicaciones, experiencias y prácticas de personas callejeras en Bogotá
}

Street Cycle: Claims, Experiences and Practices of Street People in Bogota

\section{REsUMEN}

La vida en calle es una experiencia múltiple y compleja para las personas que la viven. Una entidad de espacios, tiempos, prácticas y relaciones sociales constituye lo que estas personas -que se denominan callejeras- llaman la "calle". A través de una apuesta etnográfica, este artículo busca analizar la complejidad de estas experiencias y prácticas en la ciudad de Bogotá, explorar el punto de vista de las personas callejeras -y así sus reivindicaciones-, y problematizar el desfase, los desajustes, entre la mirada sobre su propia condición de vida y cierta mirada institucional y dominante.

Palabras clave: calle, uso de drogas, violencias, "habitantes de calle", etnografía, Bogotá.

\section{ABSTRACT}

Homelessness is a multiple and complex experience for the people who live it. An ensemble of spaces, temporalities, practices, and relationships constitute what "street people" - personas callejeras in their own terms - call "the street". Through an ethnographic approach, this paper looks forward to analyse the complexity of these experiences and practices in Bogota, to explore the street people's point of view and claims, and to question the gap and discrepancies between their

\author{
Nataly Camacho Mariño \\ Laboratorio de Cambio \\ Social y Político (LCSP), \\ Universidad de París, Francia. \\ $\square$ natcamachomarino@gmail.com \\ (1) ORCID: 0000-0003-1015-6474 \\ s) Google Scholar
}


own perspective about their life condition and certain institutional and dominant perspectives.

Keywords: street, drug use, violence, homelessness, ethnography, Bogota.

\section{Introducción}

10 Ya me estaba pareciendo a un 'desechable", fue la frase que utilizó "Lasso" mientras me presentaba a su mamá -un día de visitas en la cárcel La Picota de Bogotá, donde estaba detenidoy le explicaba cómo nos habíamos conocido. Para él, en el momento de nuestro encuentro, estaba en la peor condición posible en calle: "parecía un 'desechable".

Lasso tenía veintitrés años cuando lo conocí durante el trabajo de campo para mi investigación sobre vida en calle en Bogotá, y, particularmente, sobre la presencia física y simbólica de los espacios urbanos de venta y uso de drogas - conocidos en Colombia como ollas- en el centro de la capital. Él consumía bazuco ${ }^{1}$ (pasta base de cocaína), frecuentaba las ollas diariamente y dormía algunas noches en la calle y otras, cuando tenía algo de dinero, pagaba una "pieza" - un cuarto en una pensión o paga diario del centro de la ciudad-. Su principal actividad para conseguir algo de dinero y mantener su consumo dependiente de bazuco era el robo de espejos retrovisores, bicicletas o celulares. De hecho, su encarcelación se dio por el robo a mano armada (con un cuchillo) de una bicicleta.

De vez en cuando, Lasso iba a instituciones públicas de acogida para población "habitante de calle" - según la categoría administrativa utilizada en Colombia-, donde permanecía algunas horas, podía bañarse, comer y lavar su ropa. Es precisamente en una de estas instituciones donde nos conocimos. En el relato sobre nuestro encuentro que narra a su madre, Lasso hace referencia a su relación con las instituciones. Para él, el "haber tenido" que acudir a la institucionalidad significaba estar en una situación "difícil" en calle, que lo había llevado a "parecerse" a un "desechable" (¡No a convertirse en uno!). Sin embargo, tanto él, como muchas otras personas que conocí y quienes reivindicaban la misma diferencia entre ellas y los "desechables" - hablaban de "parecerse" y no de "convertirse"-, 
eran consideradas en el lenguaje administrativo e institucional dentro de la misma categoría de "habitantes de calle".

En este artículo busco, entonces, explorar y analizar cuáles son las prácticas y las experiencias cotidianas de las personas callejeras -según el término con el que ellas mismas se identifican-, que les permiten reivindicar la diferencia entre ellas y quienes ellas denominan los "desechables". Se trata de una diferencia sutil, y ellas lo saben, pero esta es crucial para entender qué significa la calle para estas personas, así como para comprender sus trayectorias de vida en calle.

Este artículo y mi investigación de tesis doctoral, de la cual emergen las reflexiones aquí planteadas, se desarrollaron desde una apuesta etnográfica; es decir, entendiendo la etnografía como enfoque, método y texto, siguiendo los análisis de Rosana Guber (2011). Se tratará aquí de comprender apartes de la realidad social de la vida en calle en Bogotá, desde la perspectiva de las personas que la viven. De esta manera, me sumo a las investigaciones que han señalado la importancia y la pertinencia del trabajo etnográfico con poblaciones que se encuentran en condiciones de extrema precariedad y vulnerabilidad en contextos urbanos, debido a las relaciones personales que permite, a las interacciones más horizontales que surgen desde estas y a la reflexividad que suscita sobre la presencia del etnógrafo o etnógrafa (Bouhnik, 2007; Bourgois, 2013; Epele, 2010; Girola, 2007; entre otros).

El trabajo de campo que ha permitido las reflexiones aquí sugeridas se lleva desarrollando desde el año 2007. Entre el 2007 y el 2011, la investigación etnográfica se desarrolló directamente en contextos callejeros, principalmente del centro de Bogotá, con visitas semanales y recorridos acompañada de personas callejeras. Desde el 2014, la inmersión en el campo se ha realizado de forma intensiva y constante, tanto en escenarios callejeros (incluidas algunas ollas del centro de la ciudad) como institucionales (mayoritariamente públicos), y haciendo parte de relaciones de amistad con las personas conocidas y, en algunos casos, con sus familias. Asimismo, realicé entrevistas y mantuve conversaciones con funcionarios de diferentes instituciones públicas de atención y con comerciantes o residentes de los barrios donde se encontraban las ollas. Entre el 2014 y el 2019 realicé más de treinta meses de trabajo de campo divididos en cinco estadías. Durante la primera estadía de cuatro meses, tuve acceso a dos centros de acogida de jóvenes en situación de calle dos veces a la semana. Paralelamente a estas visitas institucionales y, posteriormente, en las demás estadías de campo, continué la investigación directamente en contextos callejeros, frecuentando las ollas, acompañando a diferentes 
personas en sus actividades diarias y haciendo con ellas largos recorridos por la ciudad, que marcaron también nuestras largas conversaciones.

Las redes sociales como Facebook y WhatsApp me siguen permitiendo, en tiempos de aislamiento, debido a la crisis sanitaria ocasionada por la pandemia de Covid-19, seguir en contacto con algunas de estas personas y continuar "de otras formas" nuestras conversaciones y afianzar nuestros lazos de apoyo y amistad (Camacho Mariño y Rodríguez Lizarralde, 2019). De hecho, el uso de redes sociales y de dispositivos móviles, incluso en la vida en calle, pone en evidencia ese esfuerzo de las clases populares de no quedarse desconectados en una sociedad donde el acceso y uso de la tecnología representa otra forma de desigualdad social (Reygadas, 2008).

Este artículo está estructurado en cuatro apartados, más los comentarios finales. En primera instancia, se analizan ciertas categorías utilizadas en contextos callejeros o para hablar de ellos. En segundo lugar, serán exploradas las trayectorias de vida de personas en situación de calle. En tercer lugar, hablaré de las prácticas que atraviesan la vida en calle de estas personas y el valor que ellas les dan. Finalmente, desarrollo el concepto de "ciclo de la calle"; un ciclo, entre espacios callejeros e instituciones, que les permite "resistir" en esta condición de vida extrema.

\section{Repensando las categorías para acercarnos a la calle}

"Habitantes de calle" es la categoría institucional, y para efectos administrativos, usada en Colombia para hacer referencia a las personas conocidas como "población en situación de calle" en otros países hispanohablantes de América Latina, "moradores de rua" en Brasil, "sin techo" en España, "homeless" en países anglófonos, "sans-abri" o "sans domicile fixe" en países francófonos, por dar algunos ejemplos. Esta categoría ha sido adoptada más ampliamente en el lenguaje mediático y común como "políticamente correcta", diferenciándose así de los términos "indigentes" o "desechables", y se ha incorporado igualmente en el lenguaje científico. Una mirada hacia trabajos en ciencias sociales que tratan sobre esta población en el contexto colombiano, pone en evidencia que "habitantes de calle" se ha convertido en una categoría que se moviliza sin una perspectiva crítica de lo que significa, de la construcción del Otro que ella conlleva y de los contextos socio-históricos donde ha sido usada hasta hoy.

La historia del nacimiento y la asimilación institucional y social de la categoría "habitantes de calle" es larga y compleja, y el espacio de este 
artículo no me permitirá desarrollarla. Empero, vale la pena decir que esta apareció en Bogotá hacia mediados de la década de los años noventa del siglo XX, en un clima de reivindicaciones sociales y políticas de colectivos artísticos, sociales y universitarios que trabajaban con esta población, en momentos donde las prácticas de violencia relacionadas con la "limpieza social" o el "exterminio social" como lo llama Carlos Perea Restrepo (2016), se recrudecían en la capital colombiana.

No obstante, aunque la categoría "habitantes de calle" se presentó en su momento de aparición, en oposición al término "desechables" -ampliamente utilizado en contextos urbanos en Colombia para hablar de esta misma población y usado por grupos de "limpieza social"-, el uso posterior de la categoría en el ámbito institucional, administrativo y social continúa re-produciendo representaciones sociales vinculadas a "una problemática" de miseria, suciedad, delincuencia, ilegalidad, violencia $\mathrm{y}$, por ende, peligro. Volviendo así, a la imagen de ser la causa de los problemas de seguridad en las ciudades (Camacho Mariño, 2018), legitimando medidas represivas (abuso de la fuerza policial, desalojos, desplazamientos intraurbanos, etc.), la estigmatización y la violencia misma de exterminio social. En este último caso, el uso del término "desechables" ha contribuido a la institución de una definición social (Bourdieu, 1982) que reducía a estas personas, y las reduce aún, al ámbito de "desechos" que deben ser "limpiados".

Durante mi trabajo de campo en contextos callejeros bogotanos, principalmente en y alrededor de los espacios urbanos conocidos como ollas, las numerosas personas que conocí ${ }^{2}$, hombres, mujeres ${ }^{3}$, de diversos grupos etarios entre los catorce y los sesenta años, no se reconocían como "habitantes de calle", pese a ser reconocidos institucionalmente como tales. Esta categoría era usada muy raramente y solo para ponerse en relación con escenarios institucionales. Algunas personas preferían no acceder a derechos, como tener un documento de identidad, si esto implicaba pasar por la intermediación de los servicios de instituciones donde serían registrados como "habitantes de calle".

\footnotetext{
Durante el conjunto del trabajo de campo realizado he conocido y conversado con más de doscientas personas con trayectoria de vida en calle. Al menos a la mitad de ellas las he vuelto a ver más de una vez, pudiendo conversar de nuevo y, en algunos casos, manteniéndonos en contacto durante varios meses. He seguido de cerca durante varios años la trayectoria de vida de quince personas, de quienes he podido conocer a sus familias. Es importante aclarar que he podido realizar observaciones en espacios callejeros e institucionales donde se concentran cientos de personas que se dicen callejeras.

Utilizo aquí las categorías "hombres" y "mujeres" desde la identidad de género en la que se reconocen las personas que conocí. Mi trabajo se desarrolló principalmente con hombres y mujeres cisgénero y transgénero.
} 
En la realidad observada etnográficamente, otras categorías y términos eran movilizados por las personas para hablar de ellas, de su relación con la vida en calle, y para diferenciarse entre ellas. La mayoría de las personas que han hecho parte de mi trabajo se dicen "de la calle" o "callejeras": "Yo soy un(a) callejero(a)" o "yo soy de la calle" son expresiones que permean las presentaciones de unos y otras. "Ñeros", "ñeras", "loquitos", "loquitas", y hasta el mismo término "desechables", son categorías que circulan en contextos callejeros y que permiten pensar la diferencia, construir un Otro en calle. Un Otro, Otros, que la categoría institucional invisibiliza con el peso de su homogeneidad aparente, creando así un desfase entre su manera de entender una realidad social y la manera como esta realidad es vivida por aquellas y aquellos que se confrontan día a día a ella.

Esta discusión sobre la categoría usada para denominar a las personas abre también preguntas y debates sobre qué es la calle, y sobre todo la calle que las personas que la viven revindican. Pues el término "calle", más allá de la denominación de un espacio público y urbano, tiene, para las personas que se dicen "de la calle" o callejeras, un significado más complejo. La calle representa una experiencia, como diría Claudia Girola (2007) en relación con las personas sans-abri en Francia. Una experiencia, que yo llamaría múltiple, y que se sitúa en una red de espacios urbanos y sociales. La vida cotidiana no se desarrolla para estas personas en una calle de la ciudad, sino en la Calle, no solo haciendo referencia a una delimitación geográfica, sino a un "territorio social", retomando aquí, para el contexto callejero bogotano, el término utilizado por Jean-François Laé y Numa Murard (1985, p. 117)4. Se trata de una entidad constituida de espacios, de interacciones sociales, de relaciones con pares, de prácticas de sobrevivencia en una condición de vida extrema y de experiencias que en el caso bogotano están vinculadas con el uso de drogas - principalmente de bazuco-, la "farra" (fiesta), el robo, entre otras (Camacho Mariño, 2018). A lo largo de este documento utilizaré el término "Calle", en mayúscula, para hacer referencia a este "territorio social" y "calle" en minúscula para hablar de una definición más genérica de espacio público o "fuera de casa".

En el caso de las personas con quienes he realizado mi trabajo de campo, las ollas son espacios que atraviesan toda su experiencia de vida en Calle y que hacen parte central del "territorio social" que la constituye. Desde la definición comúnmente aceptada, vehiculada por los medios de comunicación, se trata de "lugares de tráfico y uso de drogas". 
Empero, hay varios tipos de ollas. Las características y las diferencias entre estas, que son reconocidas por las personas que las frecuentan, participan en el proceso que lleva a la vida en calle y, por supuesto, en la experiencia callejera que esta condición de vida implica.

De manera general, por un lado, están las "casas-ollas", que son espacios privados (cerrados), donde se produce, comercia y consume drogas. Estos lugares tratan de mantenerse discretos a los ojos de la policía y pueden encontrarse en cualquier barrio de la ciudad. Por otro lado, están las ollas llamadas "madre", que ponen en relación el espacio público (ciertas calles) y espacios privados (las edificaciones que hacen parte de estas calles) donde también se produce, se comercia y se consume drogas. La principal diferencia entre estos dos tipos, más allá del tamaño y el uso del espacio público, es el lugar que ocupan en la ciudad. Las segundas representan "topografías específicas", retomando las palabras de Dominique Kalifa (2013). Se trata de espacios urbanos reconocidos socialmente (por los diversos actores sociales) por sus economías informales y marginales, por la pobreza, por el consumo de drogas ilícitas y lícitas, por prácticas delictivas, por la precariedad de sus edificaciones, por su "suciedad" y "desorden". La ubicación de estas ollas es reconocible y, en el caso bogotano, histórica. Aquellas en las que he realizado trabajo de campo, conocidas en las últimas décadas como las más importantes de la capital (y peligrosas en términos institucionales y mediáticos), son La Ele, el Samber y Cinco Huecos.

La Ele ha sido denominada en el lenguaje mediático como El Bronx. Situada en un sector comercial del centro de Bogotá y constituida por tres calles, en su interior se encontraban diversos tipos de establecimientos festivos, como tabernas, bares o discotecas. Varias redes de tráfico de droga compartían este espacio, representadas por las diversas "marcas" de bazuco que eran vendidas. Un grupo armado conocido como los sayayines se encargaba de la "seguridad" del lugar, respaldados por la presencia de campaneros en las diferentes entradas. Si bien el espacio de la olla estaba delimitado a tres calles determinadas por barreras materiales, su influencia sobrepasaba este rango y muchos comerciantes de la zona pagaban por seguridad a las redes que controlaban la olla. En este lugar se realizó una operación de desalojo y de demolición que comenzó en mayo de 2016 y que terminó en diciembre de 2019. Muchas de las personas que habitaban y frecuentaban este lugar, y con quienes guardo contacto, se encuentran ahora en otras "topografías específicas" como La Favorita y Santafé, también ubicadas en el centro de la ciudad y relacionadas históricamente a la prostitución, pero que con la intervención en La Ele se han 
venido transformando en los últimos años, integrando de forma intensiva el tráfico de drogas.

El Samber se sitúa en el barrio residencial de San Bernardo. Algunas calles de este barrio son consideradas la olla, debido a la presencia de "marcas" de bazuco y de establecimientos de fiesta y consumo. Aquí, las barreras son más simbólicas que materiales. A pesar de varias intervenciones que se han realizado, posteriores a las de La Ele, esta olla sigue teniendo una gran importancia como lugar de venta y consumo de drogas. A diferencia de estas dos primeras ollas, en Cinco Huecos el consumo se realiza principalmente en el espacio público y no en establecimientos. Allí es posible encontrar también varias "marcas" de bazuco. Esta olla se sitúa en un sector comercial, cerca de La Ele.

De la categoría de ollas-madre, hace parte igualmente El Cartucho, un sector del centro de la capital que ha sido considerado como la primera y la olla más grande que ha tenido la ciudad. Se trababa de un barrio, denominado administrativamente como Santa Inés, donde se concentró por varias décadas la pobreza extrema, el uso y venta de drogas y múltiples formas de economía marginal. Considerado durante varios años el lugar más peligroso de la ciudad, este sector fue desalojado y demolido entre finales de los años noventa y comienzos de los años dos mil. Aunque en el lugar que ocupaba se encuentra hoy el Parque Tercer Milenio, en la memoria de las personas que lo conocieron su recuerdo sigue muy presente. Su existencia material en su momento y hoy simbólica, ha marcado la trayectoria de vida en calle de miles de personas en Bogotá.

Si bien las ollas no representan la misma realidad social que Vita, el asilo en Puerto Alegre, Brasil, a partir del cual João Biehl (2005) desarrolló la noción de "zona de abandono social", estos espacios urbanos podrían ser pensados desde esta noción. En el caso de las ollas, el abandono es sin duda paradójico y múltiple. El gobierno nacional y el local no han tenido una reacción real frente a esta presencia, y cuando lo hacen, no es en favor de la protección de la población que allí se encuentra, sino en nombre de medidas neoliberales de "seguridad" (Wacquant, 2004). Redes de tráfico, vinculadas con grupos paramilitares, crean zonas de abandono social como fronteras en medio de la ciudad, donde además del uso de drogas, promueven espacios festivos sin límites, generando una "mercantilización de la fiesta" (Camacho Mariño, 2018; Crozat y Founier, 2005). La mirada social dominante estigmatiza y menosprecia a las personas callejeras que frecuentan las ollas, participando así de la segregación de esta población, y algunas veces motivando la "limpieza social". 
Realidades sociales semejantes a las de las ollas bogotanas, no solo se encuentran en otras ciudades colombianas (Marulanda Gómez, 2013), sino en otras ciudades alrededor del mundo. La globalización del mercado de la droga ha conducido a que prácticas y experiencias asociadas al consumo de drogas se mundialicen también y tengan un impacto fuerte en las poblaciones más desfavorecidas, quienes son además estigmatizadas y criminalizadas. Es el caso de las cracolândias en varias ciudades brasileñas, o del mercado de crack en la Plaza de Stalingrad, o en la Puerta de la Chapelle en París, por dar algunos ejemplos. Sin embargo, es importante decir que las relaciones que se han establecido desde hace varias décadas entre las ollas y actores armados, principalmente paramilitares, da a estos espacios en Colombia una especificidad marcada y manifestada por el control social y territorial ejercido por medio de diversas prácticas de violencia que van desde una violencia de lo insoportable (Naepels, 2013), en el caso de las "casa de pique"5 que se han hallado en algunas ollas, hasta una violencia cotidiana (Scheper-Hughes, 1993), inmersa en las interacciones más ordinarias.

\section{La extensión de la Calle en el espacio y el tiempo}

Las trayectorias de vida de las personas que he conocido a lo largo de mi trabajo de campo son heterogéneas. Algunas han "llegado" a la Calle y otras han nacido allí, en contextos callejeros como las ollas del Cartucho o La Ele. En el caso de estas últimas, se trata principalmente de personas de más de treinta años, a quienes su relación con la Calle como condición de vida se impone desde su nacimiento y sus vínculos familiares. Es importante mencionar que, no todas las personas que conocí y que nacieron en Calle siguen viviendo en la calle.

Por un lado, están las personas que pagan un cuarto en un inquilinato, lejos del centro de la ciudad para vivir con sus parejas y/o hijos. Por otro lado, aquellas que trabajan actualmente como educadores en las instituciones públicas de asistencia a población "habitante de calle". Sin embargo, tanto unas como otras, siguen teniendo vínculos con la Calle, entendida aquí como "territorio social". Quienes se instalaron fuera del centro de la ciudad, trabajan en los buses - de TransMilenio u otrosvendiendo dulces u objetos, y continúan visitando las ollas regularmente, aunque no cotidianamente, pues allí se encuentra su círculo de sociabilidad más próximo.

Lugares de tortura y desmembramiento de cuerpos, comúnmente asociados en Colombia con la presencia y control de grupos paramilitares. 
Y quienes trabajan en las instituciones, lo hacen desde la valorización de su experiencia en Calle. Ellas y ellos son considerados "profes callejeros" o "educadores callejeros", en su término más formal. Es decir, su trayectoria de vida en Calle se traduce aquí en una experiencia (en términos laborales), que permitiría a la institución crear un "diálogo horizontal" con la población a quien va dirigida la atención ${ }^{6}$. Así, sin tener generalmente una formación para este trabajo, lo que legitima su ejercicio es, sobre todo, como lo ha mencionado Maurizio Bergamaschi (2016), refiriéndose a un programa equivalente de "operatores pari" en Italia, su capacidad de "comprender los saberes, la historia y las expectativas" de las personas que llegan a los hogares y la credibilidad que ellas y ellos tienen frente a los destinatarios de los servicios (pp. 374-378).

En el caso de las personas que han "llegado" a la Calle, como ellas mismas lo dicen, se trata de personas de grupos etarios variados, entre la adolescencia y la tercera edad. Sin embargo, los relatos e informaciones que utilizaré aquí, para efecto del análisis, representan la experiencia de jóvenes entre los catorce y los treinta y cinco años, pues es el espectro de edades de la mayoría de ellas. Si bien la "juventud" es una construcción social siempre relacional, como ya lo ha dicho Pierre Bourdieu (1978), me permitiré hablar aquí de jóvenes callejeros desde una formulación socialmente reconocida que es, en términos generales, también reconocida por las personas que conocí, y que me permite, para la reflexión, reunir trayectorias de vida con similitudes importantes. Según los jóvenes callejeros para quienes la Calle se convirtió en su condición de vida, esta es entendida como un proceso. Es el camino entre la experiencia vital en el seno de sus familias y la experiencia relacionada a las ollas localizadas en el centro de la ciudad.

Paula tenía quince años cuando la conocí. Ella vivía con su padre y hermana en Soacha (municipio periférico a Bogotá), antes de llegar y permanecer en el centro de la ciudad en los alrededores de las ollas. En nuestro primer encuentro, en una institución pública para mujeres jóvenes, algunas de las primeras cosas que me dijo, hablando de su edad y su vida actual, fue que "comenzó a coger la Calle" cuando tenía doce años. Cuando le pregunté lo que quería decir por "coger la Calle", me dijo que había dejado de ir al colegio para quedarse todo el día en las calles de su

\footnotetext{
Este programa de "educadores callejeros" fue una apuesta que empezó a desarrollar el fundador del Instituto Distrital para protección de la Niñez y la Juventud (Idipron), el Padre Javier de Nicoló desde los años setenta, en búsqueda de generar en las personas - generalmente niños conocidos como "gamines" en la época - una mayor confianza hacia los servicios propuestos por el Idipron. No obstante, el "diálogo más horizontal" que busca este programa no deja de ser una ilusión, pues por definición se trata de una relación asimétrica entre la institución y sus beneficiarios.
} 
barrio con sus amigos, fumando marihuana y yendo a fiestas. La relación con su padre se deterioró durante este periodo y a los trece años Paula dejó la casa parental.

El caso de John, un joven de veintiún años al momento de nuestro encuentro, es similar. Él comenzó el uso de drogas en el colegio, principalmente de marihuana, cuando tenía catorce años. Durante al menos dos años de consumo regular, él continuó sus estudios de secundaria, al mismo tiempo que buscó nuevas experiencias de uso de drogas y fiesta. John creció con su abuelo en una ciudad de la costa Caribe colombiana, en un barrio "pobre" - como él lo define-. Cuando el tiempo en Calle se intensificó, y ya no pudo mantener su rendimiento en el colegio, una de sus tías, argumentando las "malas amistades" con las cuales se relacionaba John, decidió enviarlo a Bogotá donde vivía su padre. En la capital, John continuó con el uso de marihuana y volvió a "coger la calle", como él mismo lo expresó: "mi papá no supo cómo manejar la situación y unos meses después yo cogí la calle otra vez. Me profundicé más en las drogas, el robo, lo que es la calle, ¿si pilla?".

La referencia a las "malas amistades" es recurrente en las historias de muchos jóvenes. Ellos responsabilizan en cierto grado a sus amigos de la época sobre su situación actual, pues fue con el grupo de pares que consumieron algún tipo de drogas la primera vez o que salieron a robar, agregando muchas veces con tristeza y rabia "esos no eran verdaderos amigos". La misma referencia la hacen también las familias. Para las madres, abuelas, tíos y hermanos de algunos jóvenes a quienes he tenido la oportunidad de conocer, la explicación de la condición de vida actual de ellos se encuentra en las "malas amistades" del barrio con quienes pasaban "tanto" tiempo en la "calle", el "parque" o la "esquina".

La importancia de "amistades" en la trayectoria de vida en Calle ha sido también señalada por Philippe Bourgois (2013) en su libro sobre El Barrio de East Harlem en Nueva York, a partir de un trabajo etnográfico desarrollado entre 1980 y 1990. Para este autor, el grupo de pares ejerce una fuerte influencia en la llegada a la calle y a la delincuencia durante la adolescencia, pues los aprendizajes que se ejercen en grupo participan en la construcción de una identidad de la Calle que pasa por rituales como el primer robo. Cabe decir que los análisis desarrollados por Bourgois se refieren principalmente a la presencia masculina en Calle. En el caso de mi investigación, siendo mujer pude acercarme a mujeres jóvenes. Para muchas de ellas, el proceso hacia la vida en Calle comenzó por la influencia de un grupo de amigas "terribles", "loquitas" o "brinconas" -por utilizar algunos de los adjetivos que ellas usan-, o por la influencia 
del primer novio en la adolescencia y de su grupo de pares, en este caso masculino.

Jóvenes callejeros como Paula, John, Lasso y otros hombres y mujeres que conocí, crecieron todos en las márgenes urbanas en Colombia (Auyero et al., 2015). Barrios generalmente ubicados en los bordes de la ciudad o en áreas del centro donde la pobreza y la extrema pobreza han sido segregadas. Ellas y ellos han comenzado el uso de drogas lícitas e ilícitas en el colegio, principalmente en la adolescencia, y la mayoría de ellos, como Paula y Lasso, dejaron sus estudios debido a que habían comenzado a "coger la calle".

Esta expresión, "coger la calle", es indicativa de cómo ellas y ellos conciben el espacio-tiempo de la vida en Calle. Esta evoca la progresión en su trayectoria en esta precaria condición de vida. "Coger la calle" se refiere al momento en que comenzaron a pasar más y más tiempo en contextos callejeros. Estos no son solo espacios públicos, sino espacios donde las experiencias callejeras, como el consumo de drogas y fiestas toman lugar. Inicialmente, la experiencia callejera comienza en los alrededores de la residencia familiar, en parques, esquinas, terrenos deportivos y pequeñas ollas del barrio. Durante este periodo, cuando los jóvenes están "cogiendo la calle", ellos continúan viviendo con sus familias. Ellos alternan entre la Calle y la casa, pero la relación con la familia, muchas veces de por sí complicada, se vuelve insostenible a causa del uso de drogas, los problemas en el colegio y los conflictos diarios con los vecinos.

La situación familiar de Lasso, por ejemplo, se caracterizaba por un contexto violento y precario cuando él comenzó a "coger la calle". Además de las dificultades económicas, su padre golpeaba a su madre, a sus hermanas y a él. "Coger la calle" con sus amigos fue para Lasso una suerte de escapatoria vis-à-vis de esta situación. El consumo de drogas, los conflictos en el colegio y el largo tiempo que pasaba fuera de la residencia familiar agravaron la relación con su padre y la violencia aumentó. La Calle, con las experiencias ahí vividas y las relaciones con el grupo de pares, se convierte en un escape, un refugio; esta se vuelve el lugar "para estar", "parchar", para vivir, con la intención de evitar a su padre.

Si usamos la expresión utilizada por John, Lasso se "profundiza más" en la Calle hasta dejar la residencia familiar, vivir en las calles del centro de la ciudad y frecuentar las ollas. Su madre y hermanas ya no podían responder a la violencia, a la precaria situación económica y a la relación conflictiva entre Lasso y su padre. Ellas no pudieron ayudar a Lasso como él lo esperaba y, como es el caso de la mayoría de los jóvenes 
que conocí cuando su familia no pudo ayudarles y esta no constituyó un apoyo, los jóvenes buscaban en otras personas ese soporte. Estas personas eran generalmente sus amigos, quienes se encontraban en condiciones similares (Bouhnik, 2007). Para algunos jóvenes, la Calle representaba un espacio más seguro que la casa, lo que explica, muchas veces, que a pesar de que sus familias insisten en que vuelvan y que ellos sepan que pueden tener un lugar (casa) a donde ir, ellos prefieren quedarse en la Calle, pues esta representa un refugio frente a diversos tipos de violencias experimentadas en contextos familiares (Bourgois y Schonberg, 2009).

A medida que el tiempo en Calle con el grupo de pares se va extendiendo, tanto de día sin ir al colegio, como de noche sin llegar a dormir a la casa, cada vez más días a la semana, los jóvenes buscaban experiencias como fiestas y visitas a las ollas en otros barrios cercanos, luego en las ollas del centro de la ciudad conocidas por sus farras "sin parar", variedad de drogas y bajos precios. Para los jóvenes callejeros que conocí, son generalmente en las ollas ubicadas en el centro de la ciudad donde su experiencia callejera -que mientras van cogiendo la calle es reconocida desde experiencias festivas y de riesgo- se transforma en una experiencia extremadamente precaria, donde se suma la dependencia cada vez más incontrolable a drogas como el bazuco y las diversas violencias vividas en la Calle y en las ollas.

Ciertamente, es muy difícil definir en fases la experiencia callejera, pues se trata de un largo, discontinuo y complejo proceso con diferentes ires y venires entre la residencia familiar, algunas instituciones y la Calle. La experiencia, inicialmente de "lo barrial", es dirigida hacia otros sectores de la ciudad y allí aparecen las ollas ubicadas en el centro de Bogotá. Al llegar a estas ollas, la experiencia espacial y temporal de la Calle se extiende. Nuevos espacios entran en ese "territorio social". Los jóvenes usualmente mencionaban el descubrimiento de estas ollas como el momento en el que "cayeron en la Calle". Una suerte de "antes" y "después" se establece en aquel instante y es ahí cuando ellas y ellos reconocen la Calle como su espacio de vida y cuando comienza el reconocimiento de nuevas prácticas que permiten "resistir a pesar de todo", como diría Claudia Girola (2014). Según esta autora, quien ha trabajado con personas sans-abri en Francia, la expresión en francés "tenir malgré tout", que puede ser traducida por "resistir a pesar de todo", contiene un significado múltiple que incluye el "soportar", el "aguantar", con un fuerte componente de lucha (Girola, 2020). 


\section{Callejeros y “desechables": aprendizajes, prácticas y límites}

Cuando los jóvenes llegan al universo callejero del centro de la ciudad, conocen a otros jóvenes, hombres y mujeres, con una trayectoria similar, pero sobre todo, se confrontan con otras personas para quienes el tiempo pasado en la Calle es generalmente mayor a sus propias edades (de los jóvenes). Para todas las personas que conocí, esta confrontación representó un momento "extraño" o "duro", ya que ellas estaban compartiendo el mismo espacio-tiempo (ollas, calles e instituciones de asistencia) con personas consideradas por la mirada social dominante como "desechables". A pesar de que los jóvenes vienen de familias pobres y de barrios populares, la mayoría descubrió, en ese momento y con esas personas, la pobreza extrema. En estas circunstancias, así sus actuales condiciones de vida no fueran tan diferentes a las de las personas consideradas "desechables" - pues también vivían en la calle, visitaban los mismos espacios institucionales, consumían drogas y frecuentaban las mismas ollas-, los jóvenes callejeros reivindicaban y persistían en mantener una distinción entre ellos y aquellos "desechables".

El establecimiento de esta distinción tiene una importancia considerable en la manera como estos jóvenes se afirman (Girola, 2007) como personas en Calle, ya que esta significa para ellos que otra persona está en una situación aún peor que la suya (Pichon, 2010). Tal como Erving Goffman (2006) lo escribió en su clásico trabajo Estigma:

El individuo estigmatizado presenta una tendencia a estratificar a sus "pares" según el grado en que sus estigmas se manifiestan y se imponen. Puede entonces adoptar con aquellos cuyo estigma es más visible que el suyo las mismas actitudes que los normales asumen con él. (p. 127)

Los jóvenes callejeros, estratifican la condición de vida en calle y las prácticas y experiencias cotidianas que hacen parte de ella, constituyendo -desde el reconocimiento de su propia situación- un Otro (aquí los "desechables"), que representaría una suerte de límite que no hay que cruzar.

Así, esta distinción y jerarquía no está solo presente en el discurso de los jóvenes, sino que está establecida también en las prácticas cotidianas realizadas al sobrevivir, para "resistir". Entre mejor sea posible para una persona vivir en Calle -lo que significa, desde el contexto callejero, permitirle pagar regularmente una "pieza", comer bien y mantener 
un consumo diario de drogas-, más valoradas serán sus prácticas. Prácticas que se transmiten y se aprenden.

En contextos institucionales o en contextos callejeros como las ollas, parques o plazas cercanas a las ollas, los "recién llegados" en el mundo callejero del centro de la ciudad encuentran pares con quienes compartir la experiencia cotidiana. Vivir en el centro de la ciudad y devenir un visitante regular de las ollas requiere, para los jóvenes recién llegados en esta condición de vida, aprender prácticas y estrategias para mantenerse, y aprender códigos y reglas relacionadas con el universo callejero, particularmente en las ollas. Es precisamente con estos pares -quienes también establecen una diferencia entre ellos y las personas que consideran "desechables"-, con quienes los recién llegados comienzan a aprender comportamientos del universo callejero.

Yo misma fui considerada como una "recién llegada" y varias prácticas me fueron enseñadas. En el momento en el que desarrollaba mi trabajo de campo, yo compartía la misma edad de muchas de las personas con quienes pasaba tiempo en Calle, y desde esa "juventud" fui situada y legitimada. Todas las personas que conocí en espacios institucionales o en contextos callejeros, fuera de las ollas, sabían que yo realizaba un trabajo universitario sobre la vida en calle en Bogotá. Empero, dentro de las ollas, debido a que estos espacios representan fronteras tangibles en la ciudad (Camacho Mariño, 2015, 2018) y son controlados por grupos armados, ni yo ni mis acompañantes/amigos callejeros con quienes visitábamos esos espacios, hablábamos de mis intenciones investigativas como una medida de protección tanto para ellos como para mí. En estos espacios, yo era una joven más que visitaba las ollas para la "farra". El hecho de ser mujer, la confianza construida con las personas a quienes acompañaba y quienes me acompañaban, y mis conocidos dentro de las personas que habían nacido y/o crecido en estos contextos sociales, me ayudaron a pasar, sino desapercibida, al menos a no parecer "peligrosa" ante los grupos de control de las ollas.

Ser percibida como una "recién llegada" me permitió entender cómo el conocimiento práctico es transmitido en forma de consejos. Cuál es la mejor "marca" de bazuco dentro de las variadas posibilidades en las ollas, cuál es la mejor manera de llegar a las ollas después de un robo evitando la presencia de la policía, dónde comprar un buen chamber ${ }^{7}$, o hasta cómo se pueden reducir los riesgos de ser remarcada por los grupos de control para su negocio de explotación sexual... son algunas de las prácticas 
que me fueron transmitidas. Los diferentes consejos que me fueron dados estaban fuertemente mediados por cómo las personas me leían, es decir, como una mujer, y en la relación que se creaba con mi interlocutor o interlocutora. Muchas veces los hombres me advertían que este "no era un lugar para mí" y me daban recomendaciones como no quedarme mucho tiempo dentro de la olla, de comprar y fumar afuera, y si quería farra, me recomendaban estar acompañada de alguien conocido, lo que quería decir: un hombre. Las mujeres que me cruzaba dentro de las ollas me advertían de posibles peligros, me recomendaban un buen bar para pasar el rato, me mostraban cómo ellas pasaban objetos robados frente a los policías, o me repetían cuáles eran las "parlas" (historias generalmente falsas) que le contaban a la gente en la calle o en los buses para que les dieran dinero.

En medio de esas largas conversaciones acompañadas de relatos de vida, de consejos y recomendaciones, la jerarquía de prácticas era también presentada. En el caso de las mujeres, a pesar de que la prostitución es una práctica bastante común, esta no era realmente valorada, pero sí se presentaba con matices, más o menos apreciables, en función del lugar, el precio o la regularidad. Las mujeres jóvenes, como los hombres, valoraban el robo; sea cuando ellas robaban en grupo o solas o cuando servían de "campanas" o "descargas", es decir, respectivamente, cuando avisaban de la presencia o llegada de la policía o cuando eran ellas quienes debían transportar los objetos hurtados hasta las ollas donde serían vendidos.

En el caso de los hombres, trabajar para las redes de tráfico de drogas o de reventa de objetos robados, como sayayines o "manes de la seguridad" y "campaneros", era muy valorado, no solo debido a la autoridad que estos empleos representan, sino a su buena remuneración. Sin embargo, muy pocos llegan a ocupar estos cargos, pues dependen de lo "bien" relacionados que estén, del nivel de consumo de drogas que no puede ser muy elevado, del tiempo que lleven en contextos callejeros, de la reputación que tengan en Calle y de la experiencia que tengan en universos delincuenciales.

Para la gran mayoría de los jóvenes que conocí, el robo era su principal actividad para sobrevivir. Se trataba usualmente de una práctica individual de robos relativamente "pequeños" (celulares, billeteras, espejos retrovisores). Como lo señala María Epele (2010), en referencia a los jóvenes usuarios de drogas en contextos precarios en el Gran Buenos Aires, estos jóvenes callejeros que hicieron parte de mi trabajo no pertenecían a una ninguna organización del crimen; sus robos se constituían en una estrategia errática, aunque en el caso bogotano, regular. 
Para muchos de ellos -tanto hombres como mujeres-, la participación en bandas delincuenciales o convertirse en un "profesional" (con o sin armas blancas o de fuego), como lo veían en algunas personas que se beneficiaban de esta reputación en las ollas, era un ideal. Y de manera más general, las prácticas de robo funcionaban de cierta forma como un acto de revancha frente a las injusticias sociales que no solo ellos, sino también sus familias, han sufrido, y unos matices morales se asociaban a esta práctica (Bourgois y Schonberg, 2009). Robar en el norte, considerada la zona "rica" de la ciudad, a los "universitarios" o "ejecutivos" era reivindicado y valorado, mientras que "ir a quitarle a los que no tienen", en barrios pobres donde muchos de ellos habían crecido, podía ser percibido como "incomprensible" o "desesperado", visto desde el contexto callejero de las ollas del centro de la ciudad.

Las prácticas menospreciadas son todas aquellas que han sido históricamente relacionadas, desde una mirada social dominante, con la vida en la calle. Pedir limosna o reciclar son prácticas que cargan con un peso simbólico de la suciedad, de la dependencia, de la miseria y, visto desde los ojos de los jóvenes callejeros, del desprecio social y del "quedarse ahí", de "cruzar el límite" que los "desechables" ya han cruzado.

La diferencia entre una práctica valorada y otra menospreciada, y las posibilidades que estas permiten en la Calle, se encuentra en el centro de la distinción reivindicada por las personas que se dicen callejeras o "de la Calle" y a quienes ellas consideran como "desechables". A partir de allí, se definen "dos caras de la Calle": un lado "bueno" y un lado "malo", generalmente llamados en el lenguaje callejero bogotano, el lado "chimba" y el lado "maquia", respectivamente. Si un joven callejero para quien su actividad es el robo debe un día reciclar o pedir limosna, este considerará que está pareciéndose a un "desechable", porque estas prácticas se relacionan con estas personas. Sin embargo, ellos no considerarán que se están convirtiendo en "desechables", pues piensan que esta situación es transitoria y que ellos pueden cambiarla. Como Nelson -un joven que conocí en el centro de la ciudad y que nunca más volví a ver- comentó: los "desechables" son quienes "se quedan en el "pánico"'s del bazuco. Ellos se quedan en el lado "maquia".

\section{El ciclo de la Calle: del lado "chimba" al lado "maquia" y viceversa}

La posibilidad de saltar, de pasar de un lado a otro de la Calle para no "quedarse", y evitar ante todo convertirse en un "desechable", representa 
lo que he llamado el "ciclo de la Calle" (Camacho Mariño, 2018), inspirándome del "ciclo del gamín" analizado por Jacques Meunier (2000 [1977]) con los "gamines" - niños de la calle- bogotanos en los años setenta del siglo XX. Los jóvenes callejeros utilizan prácticas, como las que vimos en el apartado anterior, para sobrevivir, "resistir", vivir la Calle. Muchas de estas, les permiten mantener un consumo intensivo de drogas, pagar de forma variable una "pieza" y comprar comida. No obstante, las condiciones de la vida en Calle no dejan de ser precarias y extremadamente difíciles de solventar, así se encuentren en lo que ellos llaman el "lado chimba". El bazuco, con su efecto rápido y fuerte, y la adicción que conlleva, hace que muchos jóvenes terminen por "consumir-se" (Epele, 2010, p. 130). Sus cuerpos fragilizados por la dependencia se enfrentan además a múltiples formas de violencia en la calle y en las ollas, episodios donde generalmente terminan ellos también haciendo uso de la violencia. Las peleas callejeras a golpes o a puñal, el abuso de la fuerza policial, las formas de castigo en las ollas, la agresiones físicas y verbales por parte de transeúntes o comerciantes en ciertos sectores, sin contar las innumerables violencias de género y sexuales en contra de las mujeres callejeras, marcan los cuerpos de estos jóvenes. En el "lado maquia" hay que sumarle el hambre y la búsqueda de comida en las basuras, el frío, sus ropas y sus cuerpos mojados en una ciudad de lluvias inclementes, la suciedad que ellos no aprecian, pedir limosna que los acerca más al desprecio de la sociedad dominante... El paso entre un lado y otro de la calle hace parte integral de la vida en Calle, puede ser rápido y es constante. El límite entre uno y otro es sutil y borroso.

Una expresión utilizada por los jóvenes, que evidencia la nebulosa frontera entre los "lados" o "caras" de la Calle, es "internarse". Este verbo es usado para hablar tanto de internarse en instituciones públicas o privadas de "rehabilitación" o "resocialización" - según los términos utilizadas en estas-, como de internarse en las ollas para mantener un consumo de drogas prolongado de varios días.

El Callao: Lo máximo que duré en La Ele fueron quince días. Llegué como con doscientos mil pesos y se me acabaron en una noche. Y ahí empecé a vender la ropa, los zapatos y el celular, todo. Vendí todo. Después de que estaba en desechable, me puse a reciclar. [...] Pero después de que estaba aburrido, que no tenía bazuco, que no tenía nada, no pues qué, pues me tocó es robar porque qué más hacía. ¿Si robaba en el barrio por qué no voy a robar acá? ¿Si andaba con fierro en el barrio por qué no puedo andar con fierro o con un cuchillo pa robar acá? Entonces me dedicaba a robar. Me iba a la Décima o a la Diecinueve a robar. Después de que robaba, me iba pa 
La Ele, me compraba mi pipa, me compraba bazuco y me internaba, y duraba allá consumiendo harto tiempo. Y se me acababa el rato y me iba a reciclar o me iba a robar. [...] De ahí llamé a mi mamá y le dije: Mire madre, yo estoy acá y es pa que me venga a recoger. Es que estoy vuelto nada y quiero volver a la casa". Y vino y me recogió. [...] Yo llegué vuelto nada. Estaba vuelto mierda; con ropa de desechable, flaco, con ojeras, con todo eso.

Cuando conocí al "Callao", él había salido hacía pocas semanas de una institución privada para dejar el uso de drogas donde fue internado por iniciativa de su familia. Después de ponerse en contacto con su mamá, en el entorno familiar decidieron que lo mejor era internarlo, así el precio de esta institución representara un gran esfuerzo económico. Al momento de nuestro encuentro, su vida oscilaba entre la casa y contextos callejeros, ocultando esto último a su familia. A pesar de su "internamiento" de varios meses en la institución, la Calle seguía muy presente en su vida, era allí donde se encontraba con el grupo de pares, los mismos con quienes había decido un día ir hasta el centro de la ciudad y visitar La Ele.

A pesar de que el tiempo pasado en contextos callejeros del centro de la ciudad, no se había prolongado por varios años para El Callao, como es el caso de la mayoría de los jóvenes que conocí, en el fragmento de conversación con él, podemos encontrar algunos elementos para entender cuál fue su experiencia callejera. Hay varios puntos en común con los otros jóvenes, tales como robos, reciclaje, consumo intensivo de bazuco, deterioro corporal, y también su experiencia cuando estaba cogiendo la calle, en el barrio donde vivía con su familia, donde también robaba. Él, como los demás jóvenes, también se confrontó a su "parecido" con un "desechable" y fue justamente debido al miedo que este parecido le provocó, como él me lo dijo, que decidió llamar a su madre y aceptar su proposición de internarse en una institución privada.

En el caso de otros jóvenes que no mantenían durante su vida en Calle una relación muy cercana con su familia, pues se alejaron de ellas por los conflictos, como es el caso de Lasso, John o Paula, citados más arriba, las instituciones públicas de asistencia se convierten en esos espacios que les permiten "recuperarse" cuando su parecido con quienes ellos consideran "desechables" los asusta, pues seguir en esa situación podía implicar "quedarse" en el "lado maquia" de la Calle.

Algunas de las instituciones públicas facilitan espacios de duchas, alimentación, lavado de ropa, durante el día, otras pocas facilitan alojamiento en las noches, y otras permiten "internarse" para hacer un 
proceso de "resocialización" de varios meses. El uso de este tipo de instituciones es sin duda utilitario (Girola, 2007; Pichon, 2010) y no siempre es valorado por los jóvenes callejeros debido al enfoque religioso y moralista que pesa en estos lugares, y por ende a los juicios morales que los funcionarios de estos espacios hacen recaer sobre ellos. Muchas veces, su uso se hace para ellas y ellos necesario -a pesar de no querer estar allípara poder mantenerse y recuperarse de una condición de consumo intensivo que es difícil de controlar.

Durante el aislamiento obligatorio decretado en Colombia por la pandemia de Covid-19 entre marzo y agosto de 2020, por ejemplo, muchas personas que se encontraban en Calle y que no podían acceder a los espacios institucionales - pues estos habían cerrado sus puertas con las personas que estaban dentro-, pedían que los "patios" -como son conocidos en el lenguaje callejero- les permitieran ingresar para mitigar su propio consumo de drogas, porque estaban consumiendo más que antes ${ }^{9}$. Ya no contaban con esas pausas generadas por las reglas y los tiempos institucionales.

Pese a la relevancia de estos espacios institucionales en la vida de muchas personas, la mayoría de los jóvenes que han hecho parte de mi investigación no terminan ningún "proceso" institucional, sino que pasan en estos lugares unas semanas y luego "piden puerta" para salir de allí o se escapan saltando los muros para volver a la Calle e "internarse" en las ollas. Y así, sus trayectorias de vida en Calle se convierten en un ciclo de "internamientos" de consumo y recuperación que les permiten mantenerse en la diferencia entre ellos y aquellos a quienes denominan "desechables", y no cruzar ese límite simbólico hacia lo que alguna vez Jenny -una joven inmersa en este ciclo de la Calle- denominó la "indigencia total". Una indigencia que los reduciría a la categoría social de "desechos", y que es interpretada como una pérdida de humanidad, desde la pérdida de la capacidad de acción de pasar de un lado a otro, de darse cuenta cuando hay que "hacer algo", de no "quedarse". Estos jóvenes se piensan como sujetos activos de su condición actual y de las formas que tienen de manejarla, contrariamente a una mirada social dominante que continúa pensando a las personas en situación de calle como sujetos pasivos, y contrariamente también a la imagen que los mismos jóvenes se hacen de los llamados "desechables". Pero, ¿quiénes son en realidad esos "desechables"? ¿No se tratará aquí de una figura simbólica que les permite situarse, posicionarse, con relación a un Otro estigmatizado, para darse la fuerza de "resistir"?

Accedí a esta información por medio de relatos que fueron narrados por personas en situación de calle a miembros del Colectivo Maquia (Colectivo de investigación y creación callejeras) del cual hago parte. 


\section{Comentarios finales}

"El conformismo nace en la definición", es una frase del reconocido pintor y escultor George Braque, que no sin razón abre un clásico libro de etnografía en América Latina, A favor da etnografía de Mariza Peirano (1995). Cada grupo social atribuye categorías y términos a sus experiencias que sobrepasan las definiciones generalmente simplistas de miradas sociales dominantes, muchas veces vehiculadas por los medios de comunicación y presentes en estancias institucionales. Salir de estas definiciones impuestas sobre el universo callejero bogotano, para situarnos desde el punto de vista de sus actores y actrices sociales -objetivo de toda apuesta etnográfica- nos permite, por ejemplo, reconocer la complejidad de las experiencias y el desfase entre este punto de vista y el de la institución.

Escuchar las voces "subalternas" en las ciencias sociales, no debería representar solamente hacer uso de entrevistas o de encuestas. Escuchar estas voces debería significar para quienes investigamos comprender lo que estas voces dicen, buscar entender la manera cómo esas personas comprenden su mundo social, su realidad... para así dejar de imponer desde la academia - muchas veces sin ser conscientes de ellocategorías que pueden llegar a silenciar esas mismas voces. Si bien, es importante definir y adoptar términos con y sobre los cuales trabajamos como investigadores, y muchas veces son términos que vienen de una mirada social dominante, un primer paso sería posicionarnos y asumir, con la problematización que esto implica, desde dónde y para quién escribimos o hablamos.

A lo largo de este artículo, y más ampliamente, de mis investigaciones, he buscado entender cómo las personas que se dicen callejeras, y particularmente las y los jóvenes, viven su experiencia de vida en Calle y ponen palabras a su trayectoria. Se trata, para ellas, de una Calle que se presenta como un proceso, una experiencia, una entidad espacial, temporal y social donde, en medio de innumerables cortapisas, ellas ejercen prácticas que les permiten "resistir" y reconocer tanto el "lado maquia", como el "lado chimba" de una condición de vida al límite. Sus trayectorias de vida en Calle toman una forma cíclica -de espiral si se quiere- con rupturas y continuidades, con desajustes frente a la mirada institucional, con una expansión de espacios y de tiempos que marcan y determinan una experiencia callejera que comienza un día, pero que atraviesa luego todos sus días.

El trabajo y los análisis presentados aquí, como toda apuesta etnográfica, son una verdad parcial, sin pretensión de completitud. 
Están mediados por los actores y actrices sociales que conocí, por mi propio posicionamiento como investigadora y por las relaciones que se construyeron. Siendo mujer y joven tuve acceso a ciertas personas, relatos, conversaciones, situaciones, observaciones, lugares, que situaron mi mirada y mis interpretaciones. Este camino de investigación, y el texto que queda de él en este artículo, busca dejar abiertas preguntas y pistas de análisis, para que las voces de las personas callejeras encuentren un lugar en nuestros trabajos académicos, y podamos reconocer, como ellas ya lo reconocen, su lugar como sujetos sociales activos.

\section{Referencias bibliográficas}

Auyero, J., Bourgois, P. I. y Scheper-Hughes, N. (eds.). (2015). Violence at the urban margins. Oxford University Press.

Bergamaschi, M. (2016). Un passé qui ne passe pas: L'operatore pari dans les centres d'hébergement. En P. Pichon, C. Girola y E. Jouve (eds.), Au temps du sans-abrisme: Enquêtes de terrain et problème public (pp. 371-383). Publication de l'Université de Saint Étienne.

Biehl, J. G. (2005). Vita: Life in a zone of social abandonment. University of California Press. Bouhnik, P. (2007). Toxicos: Le goût et la peine. La Découverte.

Bourdieu, P. (1978). La "jeunesse" n'est qu'un mot. En A.-M. Métailié y J.-M. Thiveaud (eds.), Les jeunes et le premier emploi (pp. 520-530). Association des Âges.

Bourdieu, P. (1982). Les rites comme actes d'institution. Actes de la recherche en sciences sociales, 43(1), 58-63. https://doi.org/10.3406/arss.1982.2159

Bourgois, P. (2013). En quête de respect: Le crack à New-York. Seuil.

Bourgois, P. I. y Schonberg, J. (2009). Righteous Dopefiend. University of California Press.

Camacho Mariño, N. (2015). Les ollas de Bogotá: Des lieux de passage, des lieux-frontières. Travaux en cours, 11, 14-24.

Camacho Mariño, N. (2018). Une anthropologie de la rue. Pauvreté, drogues et violence dans les ollas de Bogotá (Colombie) (Tesis de doctorado). Université Paris Diderot, París, Francia.

Camacho Mariño, N. y Rodríguez Lizarralde, C. (2019). Etnografía callejera: Una propuesta desde las calles de Bogotá, Colombia. Civitas - Revista de Ciências Sociais, 19(1), 11-27. https://doi.org/10.15448/1984-7289.2019.1.30910

Crozat, D. y Founier, S. (2005). De la fête aux loisirs: Évènement, marchandisation et invention des lieux. Annales de Géographie, 643, 307-328.

Epele, M. (2010). Sujetar por la herida: Una etnografía sobre drogas, pobreza y salud. Paidós.

Girola, C. (2007). De l'homme liminaire à la personne sociale: La lutte quotidienne des sans-abri (Tesis de doctorado). École des Hautes Etudes en Sciences sociales, Paris, Francia.

Girola, C. (2014). Tenir malgré tout dans une vie à la rue. Tumultes, 2(43), 55-66.

Girola, C. (2020). ¿Qué nos pasó? Re-conociendo desde la distancia y la incertidumbre [Mesa Redonda]. IX Jornadas de Etnografía y Métodos Cualitativos [en línea]. 
Goffman, E. (2006). Estigma: La identidad deteriorada (L. Guinsberg, Trad.). Amorrortu.

Guber, R. (2011). La etnografía: Método, campo y reflexividad. Siglo XXI Editores.

Kalifa, D. (2013). Les bas-fonds: Histoire d'un imaginaire. Seuil.

Labrousse, A., y Redjimi, G. (2002). Drogues et mondialisation: Vers de nouvelles influences. Entretien avec Alain Labrousse. Agora débats/jeunesses, 27, 58-73.

Laé, J.-F., y Murard, N. (1985). L'argent des pauvres: La vie quotidienne en cité de transit. Éditions du Seuil.

Marulanda Gómez, L. (2013). La liminalidad de las "ollas": Relaciones entre la ilegalidad y la legalidad en el mercado de drogas ilícitas de la ciudad de Pereira. Revista de Antropología y Sociología: Virajes, 15(2), 73-100.

Meunier, J. (2000 [1977]). Les gamins de Bogotá. Payot \& Rivages.

Naepels, M. (2013). Conjurer la guerre: Violence et pouvoir à Houaïlou (Nouvelle-Calédonie). Éditions EHESS.

Peirano, M. (1995). A favor da etnografia. Río de Relume-Dumará.

Perea Restrepo, C. (2016). Limpieza social. Una violencia mal nombrada. Centro Nacional de Memoria Histórica, Instituto de Estudios Políticos y Relaciones Internacionales Universidad Nacional de Colombia.

Pichon, P. (2010). Vivre dans la rue: Sociologie des sans domicile fixe. Saint-Étienne: Publications de l'Université de Saint-Étienne.

Reygadas, L. (2008). La Apropiación: Destejiendo las redes de la desigualdad. Anthropos, Universidad Autónoma Metropolitana, Unidad Iztapalapa.

Scheper-Hughes, N. (1993). Death without weeping: The violence of everyday life in Brazil. University of California Press.

Wacquant, L. (2004). Punir les pauvres: Le nouveau gouvernement de l'insécurité sociale. Agone. 